\title{
Klaatu barada nikto!
}

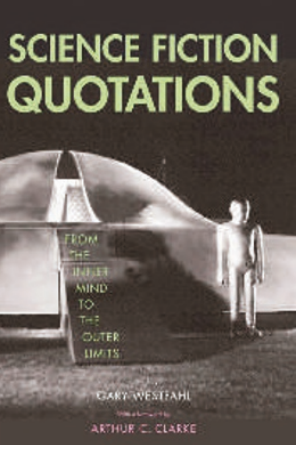

A book of science fiction quotations is exactly what you'd need were you attending a convention and were asked to put together a quiz. Those who hate science fiction will comment that were such a book compiled on the basis of literary quality, it would be even shorter than that well-known pamphlet Guide to the Marine Life of Switzerland. Not that sciencefiction authors would disagree ("usually our fiction is dreadful" - Philip K. Dick) and this is reflected in the quotations here, the result of a vast and unashamedly uncritical trawl through a century and a half of books, magazines, films and radio. Some of the entries are pithy and witty, but many are long, incomprehensible, crack unfunny jokes too cheap for Christmas crackers, or state truisms that might be more deftly expressed. The worst are poems that make Vogon sonnets read like Keats.

As editor Gary Westfahl notes, the number of quotes collected for a given author need not be a measure of quality, for a tightly written story may yield fewer bons mots than one full of rambling digressions (explaining the prominence of Robert Heinlein, whose later books consist largely of memorable backwoods aphorisms). On the other hand, some authors manage tight stories where virtually everything is quotable. If Wells and Verne were the Shakespeares of science fiction, then Douglas Adams and Terry Pratchett are its Shaw and Wilde.

Working out a deeper purpose for this book's existence is more problematic, as the editor himself offers few clues. But a twohour trawl through this book is immensely evocative, leaving you with the tang of endless time and illimitable space. As Brian Aldiss and David Wingrove commented (in Trillion Year Spree, their essential critical history of science fiction), the weird tales of H. P. Lovecraft work as psychological case histories even if they fail as literature. And to paraphrase Noël Coward, there's no denying the power of cheap music. Perhaps this is why the more literary sciencefiction authors such as C. S. Lewis loved to slum it with the pulp magazines. Even the title of this review (from the 1951 film The Day the Earth Stood Still) conjures up entire worlds and reminds us of formative reading or film-going experience, for all that it is gibberish.

Unlike mainstream literature, science fiction offers an accessible, demotic slant on the eternal verities, without the reader having to navigate the stylized clutter modern novelists feel is required to strike a pose, or tell us how clever they think they are. Science-fiction writers, in contrast, tend to say what they mean somewhat directly, in the manner of children. It is perhaps because of this emperor's-new-clothes attitude that mainstream authors and critics affect to revile, ignore - even fear - science fiction, or dismiss it as juvenilia.

Scientists in science fiction are often caricatured as emotionless drones concerned with short-term goals. But science-fiction writers have a hotline to the provisional nature of scientific truth that many scientists find elusive, though not all. As Edwin Balmer and Philip Wylie wrote in When Worlds Collide (1932): "What stupid vanity, to suppose that a thing could not happen because you could not conceive it!" - a statement congruent with, for example, Richard Dawkins' characterization (in The Blind Watchmaker) of creationists' dismissal of evolution stemming from a logically flawed "argument from incredulity".

But what I liked most amid this variegated amateur philosophizing were the flashes of wisdom from one James Tiberius Kirk, although the best example does not feature in this book. Although possibly apocryphal, I give it here in full:

SPOCK: I'm picking up a strange message on the subspace relay, Captain.

KIRK: What does it say, Mr Spock?

SPOCK: I can't believe my ears, Captain.

KIRK: I can't believe your ears either, Mr Spock.

\section{Henry Gee}

Henry Gee edits the Futures science fiction column in Nature, and is the author of The Science of Middle-Earth (Cold Spring/Souvenir).
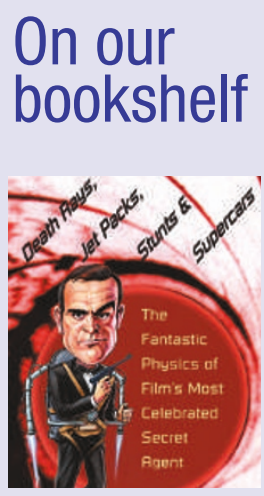

Death Rays, Jet Packs, Stunts, and Supercars: the Fantastic Physics of Film's Most Celebrated Secret Agent by Barry Parker Johns Hopkins Univ. Press: 2005. 288 pp. \$25

Invisible car aside, nearly all of James Bond's greatest stunts and gadgets have a physical explanation.

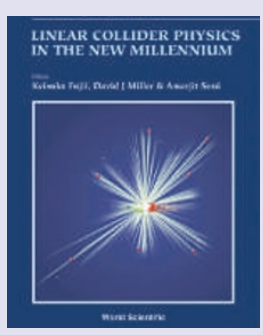

Linear Collider Physics in the New Millenium eds. Keisuke Fujii, David J. Miller \& Amarjit Soni World Scientific: 2005. 518 pp. $\$ 98$

This collection of articles explores the fundamental questions that could be addressed by a next-generation electron-positron linear collider, following on from CERN's Large Hadron Collider programme. 